\title{
KUALITAS FISIK-KIMIA PERAIRAN PANTAI DESA WAAI DAN LAJU PERTUMBUHAN RHIZOMA LAMUN Enhalus acoroides
}

\author{
Rosmawati $\mathrm{T}^{1}$, Muhammad Rijal ${ }^{2}$ \\ ${ }^{1.2}$ Jurusan Pendidikan Biologi, Institut Agama Islam Negeri Ambon \\ E-mail: rosmawatit@ rocketmail.com
}

\begin{abstract}
Abstrak: Secara visual, perairan ini memiliki karakteristik substrat yang terdiri dari substrat berpasir, berlumpur, berbatu dan patahan karang mati, sehingga memungkinkan perairan ini ditumbuhi oleh berbagai jenis lamun. Hasil penelitian memperlihatkan bahwa kondisi perairan Waai mendukung pertumbuhan lamun, dimana ukuran butiran pasir sangat kasar memiliki persentase tertinggi (30,70\%); nilai rerata suhu sebesar $28,30{ }^{\circ} \mathrm{C}$; nilai rerata salinitas $28,67 \%$; nilai rerata oksigen terlarut $5,71 \mathrm{ppm}$; nilai rerata kandungan nitrat sebesar $0,94 \mathrm{ppm}$ dan nilai rerata kandungan posfat sebesar 0,53 ppm. Populasi lamun Enhalus acoroides pada periode sampling I terdiri dari 7 kohort, sedangkan pada periode sampling II dan III masing-masing terdiri dari 8 kohort. Estimasi laju pertumbuhan adalah $1 \mathrm{~mm} /$ tahun dengan panjang maksimun 60,01 $\mathrm{mm}$ dan panjang asimptotnya adalah $66,68 \mathrm{~mm}$.
\end{abstract}

\section{Kata Kunci: Fisik-Kimia, Pertumbuhan Rhizoma, Enhalus Acoroides \\ THE QUALITY OF PHYSICS-CHEMICAL COAST WAAI AND GROWTH RATE RHIZOMA Enhalus Acoroides}

\begin{abstract}
Visually, these waters having the characteristics of a substrate consisting of sandy that of the substrate, muddy, rocky and faulting dead coral, so as to allow these waters overgrown with by various species of seagrass beds. The results of the study shows that the condition of Waai waters support development of seagrass beds, where the size of the sands of time were very rude has a higher percentage $(30,70 \%)$; value weighted the temperature as much as $28,30^{\circ} \mathrm{C}$; value weighted salinity $28,67 \%$; value weighted oxygen dissolved $5.71 \mathrm{ppm}$; value weighted nitrate content as much as $0.94 \mathrm{ppm}$; and value of weighted phosfat content as much as $0,53 \mathrm{ppm}$. The population seagrass beds enhalus acoroides in the period of sampling I consisting of 7 kohort, while the period of sampling II and III is consisting of 8 kohort. Estimation growth rate is $1 \mathrm{~mm} /$ years with a length of maksimun $60,01 \mathrm{~mm}$ and long asimptot is $66,68 \mathrm{~mm}$.
\end{abstract}

Keywords: Phisic-Chemical, Growth Rate Rhizome, Enhalus Acoroides

BIOLOGI SEL (VOL 6 NO 1 EDISI JAN-JUN 2017 ISSN 2252-858X/E-ISSN 2541-1225) PAGE 36 
Padang lamun (seagrass bed) merupakan salah satu ekosistem yang terletak di daerah pesisir atau perairan laut dangkal yang sudah sepenuhnya menyesuaikan diri untuk hidup terbenam di laut (Nontji, 2005). Komunitas lamun terdapat antara batas terendah pasang surut sampai kedalaman tertentu dimana cahaya matahari masih mencapai dasar. Secara ekonomis, lamun dapat dimanfaatkan sebagai bahan pangan, pakan ternak, bahan baku kertas, bahan kerajinan, pupuk dan bahan obat-obatan. Adapun secara ekologis, lamun memainkan peranan penting di perairan laut dangkal sebagai habitat biota lainnya seperti ikan, produsen primer serta melindungi perairan dari erosi (Fachrul, 2007).

Penelitian struktur populasi dan pertumbuhan telah banyak dilakukan terhadap hewan, namun pada tumbuhan masih sangat jarang. Penelitian struktur populasi dan pertumbuhan telah dilakukan pada jenis lamun Cymodocea nodosa oleh Duarte and SanJensen (1991), Azkab dan Kiswara (1994) serta Cunha and Duarte (2005). Penelitian struktur populasi juga telah dilakukan pada jenis lamun Cymodocea rotundata pada substrat yang berbeda di perairan Suli Pulau Ambon oleh Hulopi dkk (2006). Selanjutnya dilakukan penelitian yang sama pada tempat yang berbeda di perairan Suli oleh Tupan dan Uneputty (2009). Selama ini penelitian pertumbuhan lamun dilakukan dengan cara pengukuran panjang daun. Untuk tumbuhan, pengukuran dapat diketahui, selain melalui panjang daun, juga melalui panjang rhizoma, jumlah daun, jumlah bunga dan akar. Pengukuran pertumbuhan pada penelitian ini difokuskan pada pertambahan panjang rhizoma. Dengan rhizoma, dapat diketahui pertumbuhan sekaligus dapat diduga kelompok umur, laju rekruitmen dan laju mortalitas dari lamun.

Desa Waai adalah salah satu wilayah perairan pesisir dimana didalamnya terdapat komunitas lamun yang cukup lebat yang secara langsung maupun tidak langsung memberikan konstribusi bagi masyarakat setempat sebagai pengguna wilayah tersebut. Salah satu jenis lamun yang tumbuh pada perairan tesebut adalah Enhalus accoroides yakni jenis lamun yang memiliki produktivitas tinggi dan merupakan habitat berbagai jenis ikan, krustacea dan moluska, dimana beberapa diantaranya bernilai ekonomis penting serta berperan mencegah erosi pantai dan sebagai pendaur unsur hara (Dahuri, 2003). Pemanfaatan wilayah pesisir secara tidak terarah yang dilakukan oleh masyarakat seperti pengambilan pasir dan batu serta pembuangan limbah padat dan cair ke pantai dapat mengakibatkan kerusakan ekosistem pantai termasuk ekosistem lamun. Apabila terjadi penurunan kualitas lingkungan, produktivitas ekosistem lamun akan menurun termasuk semua populasi hewan yang berasosiasi dengan ekosistem lamun. Pemanfaatan yang tidak rasional ini sering terjadi akibat kurangnya informasi biologis dari ekosistem lamun, seperti pertumbuhan, umur, rekruitmen dan mortalitas. Oleh sebab itu, informasi yang komprehensif tentang sumberdaya lamun perlu diketahui untuk pengelolaan tanpa mengganggu kelestariannya dan tetap mempertahankannya pada tingkat produktif.

BIOLOGI SEL (YOL 6 NO 1 EDISI JAN-JUN 2017 ISSN 2252-858X/E-ISSN 2541-1225) PAGE 37 


\section{METODE PENELITIAN}

Penelitian ini dilaksanakan di perairan Pantai Desa Waai Kabupaten Maluku Tengah dan berlangsung dari bulan April sampai dengan bulan Desember 2016. Tahapan penelitian ini adalah sebagai berikut:

\section{Sampling Tumbuhan Lamun}

Pengambilan contoh tumbuhan lamun menggunakan metode transek linear kuadrat, dimana garis transek ditarik tegak lurus garis pantai ke arah laut yang dilakukan pada saat air surut dengan berpedoman pada Tabel pasang surut. Jarak antar transek adalah $20 \mathrm{~m}$. Pada transek-transek tersebut dipasang kuadrat besi berukuran $1 \mathrm{x} 1 \mathrm{~m}$ dengan jarak antar kuadrat adalah $10 \mathrm{~m}$. Di setiap kuadrat yang ada, dikumpulkan sampel lamun Enhalus accoroides.

\section{Sampel Sedimen dan Air Laut}

Di laboratorium, sampel sedimen yang telah dikeringkan ditimbang dengan timbangan digital diayak dengan menggunakan "automatic shieve shieker". Selanjutnya sampel hasil ayakan ditimbang kembali menurut ukuran butiran yang tertahan berdasarkan skala Wenworth (Hutabarat dan Evans, 1985). Analisa ukuran butiran sedimen dilakukan pada laboratorium Manajemen Sumberdaya Perairan Fakultas Perikanan Universitas Pattimura Ambon.

\section{Distribusi Frekuensi Rhizoma}

Data panjang rhizoma lamun Enhalus accoroides yang dikumpulkan selama sampling kemudian disusun ke dalam bentuk tabel distribusi frekuensi. Estimasi distribusi frekuensi mengacu pada formula yang dikemukakan oleh Riduwan (2005):

$\mathrm{C}=$ Nilai interval kelas

$$
\mathrm{C}=\frac{X n-X i}{k}
$$

$\mathrm{X}_{\mathrm{n}} \quad=$ Ukuran rhizoma terpanjang

$\mathrm{X}_{\mathrm{i}} \quad=$ Ukuran rhizoma terpendek

$\mathrm{k} \quad=$ Banyak kelas

Untuk mengetahui banyak kelas $(\mathrm{k})$ digunakan aturan Sturges yakni :

$$
\mathrm{k}=1+3,322 \log \mathrm{n}
$$

$\mathrm{n}=$ Jumlah total rhizoma yang diukur

Tabel frekuensi panjang ini digunakan untuk mengestimasi nilai rerata $(\bar{X})$ dan simpangan baku sampel (SD) dengan persamaan yang dikemukakan oleh Fowler and Cohen (1993) sebagai berikut:

$$
\begin{aligned}
\bar{X} & =\frac{\left(\sum f i X i\right)}{n} \\
\mathrm{SD} & =\sqrt{\frac{\sum f i(X i-\bar{X})^{2}}{n-1}}
\end{aligned}
$$


$\bar{X} \quad=$ Rerata dari sampel

$\mathrm{f}_{\mathrm{i}} \quad=$ Frekuensi kelas ke- $\mathrm{i}$

$\mathrm{X}_{\mathrm{i}} \quad=$ Tengah kelas ke-i

$\mathrm{n} \quad=$ Jumlah total sampel

SD = Simpangan baku sampel

Untuk mengetahui struktur populasi lamun Enhalus accoroides yang dicirikan oleh kelompok umur (kohort) berdasarkan ukuran panjang rhizoma digunakan metode Bhattacharya (1967). Selanjutnya metode ini dikembangkan oleh Sparre and Venema (1992) yang diprogramkan dalam bentuk software computer program FISAT II (version 1.2.2).

\section{Laju Pertumbuhan Rhizoma}

Untuk mengetahui pertumbuhan rhizoma lamun Enhalus accoroides dianalisis dengan menggunakan model pertumbuhan khusus Von Bertalanffy (Khouw, 2008) dari data distribusi frekuensi panjang rhizoma yang kemudian diolah dengan menggunakan software program FISAT II (version 1.2.2).

$$
S t=S \infty\left[1-e^{-k(t-t 0)}\right\rfloor
$$

St $\quad=$ Panjang rhizoma pada waktu $\mathrm{t}$

$\mathrm{S} \infty \quad=$ Panjang rhizoma asimptotik (tak berhingga)

$\mathrm{k} \quad=$ Laju pertumbuhan

to $\quad=$ Umur pada saat ukuran rhizoma sama dengan nol

$\mathrm{t}=$ Umur saat terjadinya pembengkokan pertumbuhan

Panjang rhizoma maksimum: Panjang maksimum $=0,9 \times$ Panjang rhizoma asimptotik

\section{HASIL DAN PEMBAHASAN}

Kadar nitrat perairan berkisar antara 0,13 - 2.16 ppm dengan nilai rata-rata sebesar 0,94 ppm sementara kadar posfat berkisar antara 0,01 - 1,73 ppm dengan nilai rata-rata sebesar $0,53 \mathrm{ppm}$. Selama penelitian, persentase sedimen tertinggi dengan ukuran butiran pasir sangat kasar yakni sebesar 30,705\% (Gambar 1).

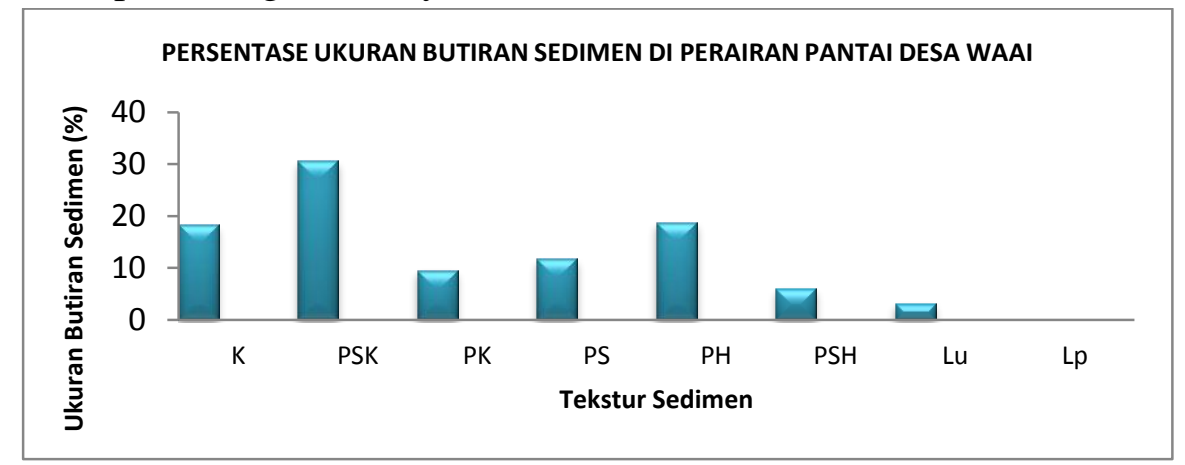

Gambar 1. Persentase Ukuran Butiran Sedimen Pada Perairan Pantai Desa Waai Berdasarkan Skala

Wenworth. $\mathrm{K}$ = kerikil; $\mathrm{PSK}=$ pasir sangat kasar; $\mathrm{PK}=$ pasir kasar; $\mathrm{PS}=$ pasir halus; $\mathrm{PSH}=$ pasir sangat halus $\mathrm{Lu}=$ lanau; $\mathrm{Lp}=$ lempung

BIOLOGI SEL (YOL 6 NO 1 EDISI JAN-JUN 2017 ISSN 2252-858X/E-ISSN 2541-1225) PAGE 39 
Analisa struktur populasi adalah analisa menyangkut penentuan sub populasi yang dicirikan oleh kelompok (kohort) tertentu. Analisis dilakukan dengan menggunakan data frekuensi dan tengah kelas panjang yang diperoleh dari pengukuran panjang rhizoma Enhalus accoroides. Hasil analisis kelompok umur dari program FISAT II diperoleh masing-masing 1 buah kurva normal selama tiga periode sampling (Gambar 2).

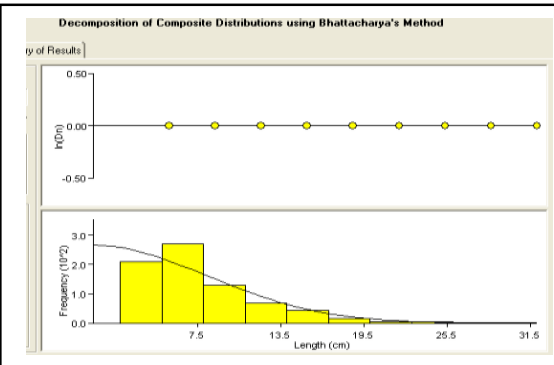

Periode Sampling 1

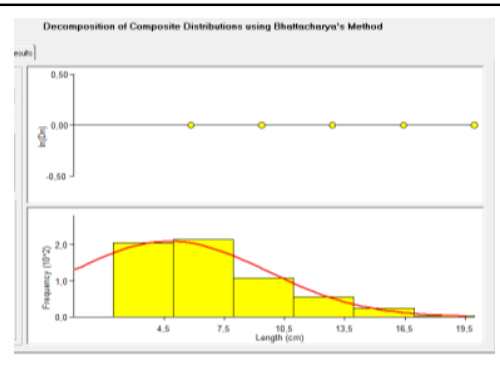

Periode Sampling 2

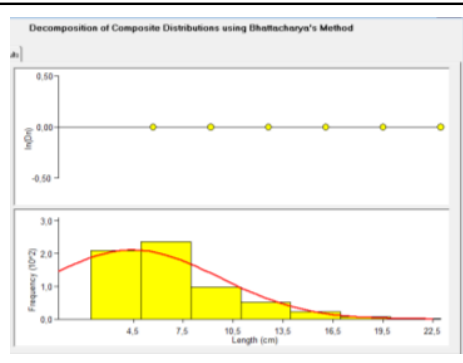

Periode Sampling 3

Gambar 2. Kurva Normal Distribusi Frekuensi Panjang Rhizoma Lamun E. accoroides Program FISAT II

Selain memperlihatkan banyaknya kurva normal yang menggambarkan banyaknya kelompok umur, metode Bhattacharya pada program FISAT juga dapat memperlihatkan nilai rata-rata, simpangan baku dan jumlah tegakan untuk masingmasing kelompok umur (Tabel 1).

Tabel 1. Estimasi Jumlah Kelompok Umur Lamun E. accoroides Hasil Program FISAT II

\begin{tabular}{|c|c|c|c|c|c|}
\hline Sampling & $\begin{array}{c}\text { Jumlah } \\
\text { Kohort }\end{array}$ & Rerata Panjang (mm) & $\begin{array}{c}\text { Simpangan } \\
\text { Baku }\end{array}$ & Populasi & $\begin{array}{c}\text { Indeks } \\
\text { Separasi }\end{array}$ \\
\hline I & 1 & 0,14 & 8,36 & 1863 & n.a \\
\hline II & 1 & 4,76 & 4,86 & 847 & n.a \\
\hline III & 1 & 4,45 & 5,19 & 910 & n.a \\
\hline
\end{tabular}

Dapat dilihat pada Tabel 1 bahwa kelompok umur (kohort) pada sampling pertama memiliki jumlah tegakan terbanyak yakni 1863 tegakan dengan ukuran rata-rata sebesar $0,14 \mathrm{~mm} \pm 8,36$ diikuti oleh kelompok umur pada sampling ketiga dengan ukuran ratarata sebesar 4,45 $\mathrm{mm} \pm 5,19$ yang memiliki jumlah tegakan sebanyak 910 tegakan, sedangkan jumlah tegakan yang paling sedikit dimiliki oleh kelompok umur pada sampling kedua (847 tegakan) dengan rerata panjang sebesar 4,76 $\mathrm{mm} \pm 4,86$. Nilai indeks pemisah (SI) pada Tabel 1 menunjukkan bahwa nilai indeks separasi lebih besar dari dua yang diperlihatkan dengan simbol n.a (not available).

\section{Parameter Fisik-Kimia Perairan}

Zieman (1975) dalam Supriharyono (2009) menyatakan bahwa tumbuhan lamun yang hidup di daerah tropis umumnya tumbuh pada daerah dengan kisaran suhu air antara $20-30^{\circ} \mathrm{C}$, sedangkan suhu optimumnya adalah $28-30^{\circ} \mathrm{C}$. Nilai suhu rata-rata yang terukur selama penelitian adalah $28,30^{\circ} \mathrm{C}$ yang mengindikasikan bahwa nilai tersebut merupakan suhu optimum yang diperlukan bagi lamun. Secara umum, salinitas yang dibutuhkan salinitas untuk pertumbuhan lamun berkisar antara 25 - 35\% (Zieman, 1975 
dalam Supriharyono, 2009), sedangkan untuk fase pembungaan, kisaran salinitas yang baik adalah antara 28 - 32\%o (Marmelstein et al, 1968 dalam Supriharyono, 2009). Nilai rata-rata salinitas selama penelitian adalah $28,67 \%$ yang berarti bahwa nilai tersebut masuk dalam kategori salinitas optimum yang mampu mendukung pertumbuhan sampai dengan proses pembungaan lamun Enhalus accoroides di perairan pantai Desa Waai.

Kandungan oksigen terlarut (DO) selama penelitian berkisar antara 4,02 - 5,81 ppm dengan nilai rata-rata sebesar $5.71 \mathrm{ppm}$ menunjang pertumbuhan lamun Enhalus accoroides. Menurut Effendie (2003), kadar oksigen terlarut yang kurang dari 4 mg/l mengakibatkan efek yang kurang menguntungkan bagi hampir semua organisme aquatik.

Menurut Davis (1990) dalam Efriyeldi (1997), sedimen yang menutupi dasar perairan memiliki berbagai variasi dalam bentuk partikel, komposisi, ukuran, sumber atau asal sedimen; dimana material yang lebih besar dan berat akan diendapkan lebih cepat pada daerah yang relative dekat dengan pantai dibandingkan material halus yang terbawa oleh arus dan gelombang ke laut lepas. Kondisi substrat dengan ukuran butiran pasir sangat kasar di perairan pantai Desa Waai mendukung pertumbuhan dan perkembangan lamun E. accoroides mengingat tumbuhan ini mampu beradaptasi terhadap berbagai tipe substrat, terutama substrat berpasir (Anonim, 2010). Substrat berperan dalam menjaga stabilitas sedimen, yaitu pelindung tumbuhan dari arus laut dan sebagai tempat pengolahan dan pemasok hara (Dahuri, 2003).

Sedimen berperan dalam ketersediaan posfor di banyak daerah perairan. Sedimen yang berukuran besar (coarse sediments) mempunyai kapasitas adsorpsi terhadap posfor yang rendah, sehingga kandungan posfor terlarut tinggi. Kondisi ini menyebabkan lamun bisa tumbuh subur.Karenanya disimpulkan bahwa kandungan posfor yang membatasi pertumbuhan lamun di daerah tropis merupakan fungsi dari ukuran sedimen, dimana kandungan posfor terlarut akan semakin rendah dengan berkurangnya ukuran sedimen (Supriharyono, 2009).

\section{Kelompok Umur}

Sparre and Venema (1992) menyatakan bahwa metode Bhattacharya bertujuan untuk memecah distribusi frekuensi panjang menjadi kurva normal. Banyaknya kurva normal yang dihasilkan menggambarkan banyaknya kelompok umur dari suatu populasi yang sedang dipelajari. Dengan demikian dapat dikatakan bahwa populasi E. accoroides yang hidup di perairan pantai Desa Waai Kabupaten Maluku Tengah hanya terdiri dari 1 kelompok umur. Kondisi ini diduga terkait dengan reproduksi E. accoroides, yakni dapat bereproduksi secara generatif dan secara vegetatif. Menurut Den Hartog (1970) dalam Dahuri (2003), lamun ini mampu mengadakan penyerbukan dan daur generatif dalam keadaan terbenam, memiliki bunga dan buah yang kemudian berkembang menjadi benih. Tumbuhan tersebut berbunga 1 kali setahun dalam jangka waktu yang relatif pendek. Semua bunga yang menghasilkan biji merupakan hasil satu kali pembungaan tahun yang sama, pertumbuhannya hampir seragam, sehingga pada akhir tahun panjang rhizomanya 
dalam batas kisaran tertentu, tetapi distribusinya normal. Puncak dari distribusi normal tersebut dapat dibedakan dengan puncak distribusi panjang rhizoma lamun hasil perbungaan atau biji tahun sebelumnya. Puncak-puncak distribusi normal tersebut jelas bagi lamun yang masih berusia muda, sedangkan bagi lamun yang telah berumur tua puncak-puncaknya tidak nyata. Selain memperlihatkan banyaknya kurva normal yang menggambarkan banyaknya kelompok umur, metode Bhattacharya pada program FISAT juga dapat memperlihatkan nilai rata-rata, simpangan baku dan jumlah tegakan untuk masing-masing kelompok umur. Menurut Sparre and Venema (1992) pemisahan dua kelompok umur yang berdekatan akan berhasil dengan baik, apabila indeks separasi lebih dari dua. Dengan demikian, dapat dikatakan bahwa pemisahan kelompok umur pada populasi lamun Enhalus accoroides telah dilakukan dengan baik.

\section{Pertumbuhan Rhizoma Enhalus accoroides}

Berdasarkan distribusi frekuensi panjang rhizoma dengan menggunakan LengthConverted Catch Curve pada program FISAT II hasil estimasi laju pertumbuhan rhizoma lamun Enhalus accoroides di perairan pantai Desa Waai adalah sebesar 0,01 mm tahun ${ }^{-}$

1. Panjang maksimun rhizoma Enhalus accoroides yang dapat dicapai selama satu tahun adalah sebesar $28,773 \mathrm{~mm}$ sementara panjang asimptotnya adalah 31,97 $\mathrm{mm}$. Hal ini mengindikasikan bahwa pertumbuhan Enhalus accoroides secara vegetatif melalui panjang rhizoma lebih sering terjadi, meskipun pertambahan panjangnya agak lambat. Kondisi ini didukung oleh pernyataan Tjitrosomo (1983) bahwa reproduksi secara vegetatif lebih umum terjadi pada jenis-jenis tumbuhan yang memiliki bagian-bagian yang terdapat di dalam substrat, seperti rhizoma. Ditambahkan pula bahwa, rhizoma adalah bagian tumbuhan yang ramping lagi panjang yang tumbuh ke arah samping di dalam substrat, dimana pada ujung rhizoma ini akan terbentuk tumbuhan baru. Bilamana tumbuhan ini telah cukup berdaun dan berakar sehingga dapat berdiri sendiri, maka rhizoma ini akan rusak dan selanjutnya akan mati. Dengan demikian, kuncup-kuncup yang terbentuk pada ketiak dan akar yang terdapat pada node akan membentuk cabangcabang, dan tumbuhan baru akan muncul pada waktu tumbuhan tetuanya mati.

\section{KESIMPULAN}

1. Desa Waai memiliki kondisi perairan (suhu, salinitas, oksigen terlarut, substrat dan unsur hara) yang mampu mendukung pertumbuhan lamun E. accoroides.

2. Hasil estimasi laju pertumbuhan rhizome lamun E. accoroides di perairan pantai Desa Waai adalah sebesar 0,01 mm tahun ${ }^{-1}$. Panjang maksimun rhizoma E. accoroides yang dapat dicapai selama satu tahun adalah sebesar $28,773 \mathrm{~cm}$ sementara panjang asimptotnya adalah $31,97 \mathrm{~mm}$. 


\section{SARAN}

1. Perlu adanya penelitian yang sama untuk spesis lamun yang lain guna memperoleh informasi lengkap tentang ekosistem padang lamun secara utuh pada perairan pantai Desa Waai Kabupaten Maluku Tengah.

2. Mengingat lamun E. accoroides di perairan pantai Desa Waai memiliki laju pertumbuhan dan laju mortalitas dalam keadaan yang seimbang (terdiri dari satu kohort) mengindikasikan bahwa kondisi lingkungan perairan pantai Desa Waai sangat mendukung pertumbuhan lamun E. accoroides. Oleh karena itu, lingkungan perairan pantai Desa Waai perlu dijaga dan dipertahankan kondisinya agar populasi lamun muda yang rentan terhadap kematian dapat terus tumbuh dan berkembang.

\section{DAFTAR PUSTAKA}

Anonim, 2009. Pertumbuhan, Produktivitas dan Biomassa, Fungsi dan Peranan. http://web.ipb.ac.id/-dedi_s., 2009. Diakses 04 Oktober 2009.

Azkab, M. H dan Wawan Kiswara. 1994. Pertumbuhan dan Produksi Lamun di Teluk Kuta, Lombok Selatan dalam Struktur Komunitas Biologi Padang Lamun di Pantai Selatan Lombok dan Kondisi Lingkungannya. Pusat Penelitian dan Pengembangan Oseanologi-LIPI.

Azkab, M. H. 1996. Pertumbuhan dan Produksi Daun Enhalus accoroides (L.f) Royle di Teluk Gerupuk, Pulau Lombok. Pusat Penelitian dan Pengembangan OseanologiLIPI.

Bhattacharya, C. G. 1967. A Simple Method of Resolution of a Distribution Into Gaussian Component. Biometrics. Pp 115 - 135.

Castro, P and M. E. Huber. 2005. Marine Biology. Saint Louis: Mosby Year Book Inc.

Cunha, A. H and Duarte C. M. 2005. Population Age Structure and Rhizome growth of Cymodocea nodosa in the Ria Formosa (Southern Portugal). Marine Biology. 146 : $841-847$.

Connell, D. W and G. J. Miller. 2006. Kimia dan Ekotoksikologi Pencemaran (Penerjemah Yanti Koestoer). Jakarta: Penerbit Universitas Indonesia (UI-Press).

Dahuri, R., 2003. Keanekaragaman Hayati Laut. Aset Pembangunan Berkelanjutan Indonesia. Jakarta: Penerbit PT Gramedia Pustaka Utama.

Duarte, C. M., and San-Jensen, K. 1991. Allometric Scalling of Seagrass Form and Productivity. Marine Ecology. Prog. Ser. 77 : 289 - 300.

Effendie, M. I. 1979. Metode Biologi Perikanan. Bogor: Yayasan Dewi Sri.

Effendie, M. I. 2002. Metode Biologi Perikanan. Yogyakarta: Yayasan Pustaka Nusatama.

Efriyeldi. 1997. Struktur Komunitas Makrozoobenthos dan Keter kaitannya Dengan Karakteristik Sedimen Di Perairan Muara Sungai Bantan Tengah, Bengkalis. Tesis. Pascasarjana Institute Pertanian Bogor (Tidk Dipublikasikan). 
English S, Wilkinson, C and Baker V. 1997. Survey manual for Tropical Marine Resources. $2^{\text {nd }} E d$. Townsville Australia: Australian Institute of Marine Science.

Fachrul, M. F. 2007. Metode Sampling Bioekologi. Jakarta: Penerbit Bumi Aksara.

Hutabarat, S., dan Stewart M. Evans. 1986. Pengantar Oseanografi. Jakarta: UI Press Cetakan Ketiga.

Kuo, J and Den Hartog. 2001. Seagrass taxonomy and Identification Key in Global Seagrass Research Methods. Elsevier Science B. Vol. 2 : 31 - 78 pp.

Nontji, A. 2005. Laut Nusantara. Jakarta: Penerbit Djambatan.

Riduwan, 2005. Dasar-dasar Statistika. Bandung: Penerbit Alfabeta.

Romimohtarto, K dan Sri Juwana. 2007. Biologi Laut Ilmu Pengetahuan Tentang Biota Laut. Jakarta: Penerbit Djambatan

Sahetapy, J. M. F. 2004. Studi Ekologi Komunitas Lamun Pada Perairan desa Ihamahu. Jurnal Triton Vol. 2 No. 1.

Supriharyono, 2009. Konservasi ekosistem Sumberdaya Hayati Di wilayah Pesisr dan Laut Tropis. Yogyakarta: Penerbit Pustaka Pelajar.

Sparre, P and Venema, S. C. 1992. Introduction to Tropical Fish assessment part-1 Manual. Marine Resources Service Fishery and Environment Division FAO Fishieries. Italy: Dept. Rome.

Tupan, Ch. I dan Pr. A. Uneputty, 2008. Struktur Populasi Lamun Cymodocea rotundata di Perairan Pantai Desa Suli Pulau Ambon. Prosiding Konferensi Nasional VI: Menuju Keberlanjutan Pengelolaan Pesisir dan Laut Demi Ketahanan dan Kesejahteraan Bangsa.

Tjitrosomo, S. S., 1983. Botani Umum 1. Bandung: Penerbit Angkasa. 